\title{
Ist die e-Zigarette Sargnagel oder Rettungsanker?
}

\author{
Bei Gesprächen zum Thema „Tabakentwöhnung“ wird dies immer gefragt: „Was sagen Sie zur \\ e-Zigarette?" Gemeint ist, wie wir Ärzte uns gegenüber Patienten, die rauchfrei werden möchten, \\ zu diesem Produkt positionieren. Soll man abraten? Oder ist sie ein probates Mittel? Teils, teils...
}

Eine Münchener Studie ergab, dass das Motiv für den Kauf der e-Zigarette bei zwei von drei Käufern der Wunsch nach Reduktion oder Beendigung des Tabakkonsums ist [1]. Grund genug, dass wir Ärzte uns zu diesem Thema positionieren.

Die Kritik an der e-Zigarette basiert im Wesentlichen auf zwei Aspekten: Der Sicherheit und der Verhaltenspsychologie.

Die Nikotinresorption erfolgt bei der e-Zigarette über die Mundschleimhaut, also ähnlich wie bei Kaugummi, Lutschtablette, Inhaler und Spray. Entsprechend langsam steigt der Nikotinspiegel, der suchterzeugende Flush bleibt aus. Die Datenlage zur langfristigen Toxizität von Propylenglykol - Hauptbestandteil des Dampfes einer e-Zigarette - ist noch lückenhaft: Empfindliche Menschen können mit Atemwegssymptomen reagieren, Daten über langfristige Effekte des inhalativen Konsums fehlen. Allerdings finden sich schon nach 5-minütigem Konsum Hinweise auf gesundheitsschädliche Effekte [2]. Ein Dilemma liegt auch in der Positionierung der e-Zigarette: Ist sie ein Arzneimittel? Dann müsste sie strengen Prüfungen standhalten und wäre wohl - sofern Wirksamkeit belegt würde - apothekenpflichtig. Oder ist sie ein Tabakprodukt? Dies hätte v.a. fiskalische Relevanz: Der Preis für nikotinhaltige Zubereitungen würde sich deutlich erhöhen.

\section{Zur Tabakentwöhnung nur bedingt geeignet}

Nur wenige Arbeiten haben den Erfolg einer Tabakentwöhnung mit e-Zigaretten untersucht. Die Ergebnisse sind gemischt [3]. Und: Mit der e-Zigarette werden viele Rituale beibehalten. Dies geht soweit, dass einige Modelle einer gewöhnlichen Zigarette zum verwechseln ähnlich sehen - bis hin zur roten LED als Nachahmung des Glimmens an der Zigarettenspitze. Der verhaltenstherapeutische Ansatz der Tabakentwöhnung wird so konterkariert. Spätestens, wenn die e-Zigarette mit nikotinfreien Flüssigkeitszubereitungen (Liquids) gefüllt wird, lässt sich über Sinn und Unsinn von deren Anwendung trefflich streiten: Das Inhalieren von Liquids z.B. mit Brathähnchenaroma hat keinerlei nikotinähnlichen Effekt, Entzugssymptome bleiben also unbeeinflusst.
Daher fällt die Beurteilung der e-Zigarette in der aktuellsten deutschen Leitlinie zur Tabakentwöhnung klar negativ aus [4]. Glaubt ein Raucher aber an die Wirksamkeit einer nach wissenschaftlichen Gesichtspunkten wenig effektiven Entwöhnungsmethode, so ist der Erfolg größer, wenn man ihn diese Methode anwenden lässt, als wenn man sie ihm ausredet und eine andere, erwiesenermaßen effektivere Methode empfiehlt [5].

Verfolgt man in der Tabakentwöhnung das Konzept der Harm Reduction, also der Verringerung von Schäden durch inhalative Noxen, so ist die e-Zigarette im Vergleich mit der normalen Zigarette die weniger schädliche Alternative. Aktuell genügt sie aber nicht den wissenschaftlichen Ansprüchen an ein etabliertes Instrument der Tabakentwöhnung.

Entsprechend mein Fazit: Ich empfehle die e-Zigarette nicht aktiv. Unentschlossenen Patienten rate ich von ihr ab. Patienten, die an den Erfolg der e-Zigarette glauben, rede ich sie nicht aus.
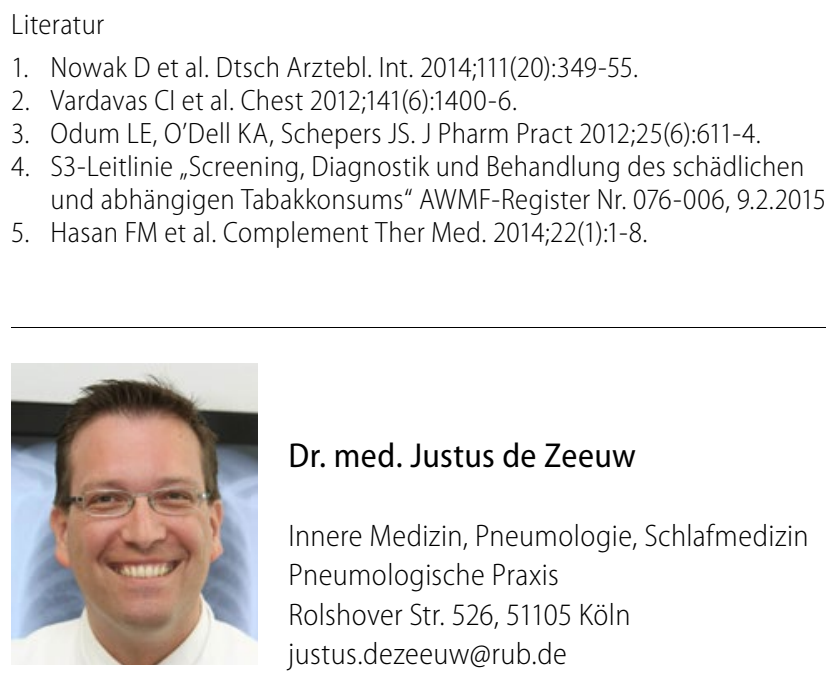

Dr. med. Justus de Zeeuw

Innere Medizin, Pneumologie, Schlafmedizin Pneumologische Praxis Rolshover Str. 526, 51105 Köln justus.dezeeuw@rub.de 